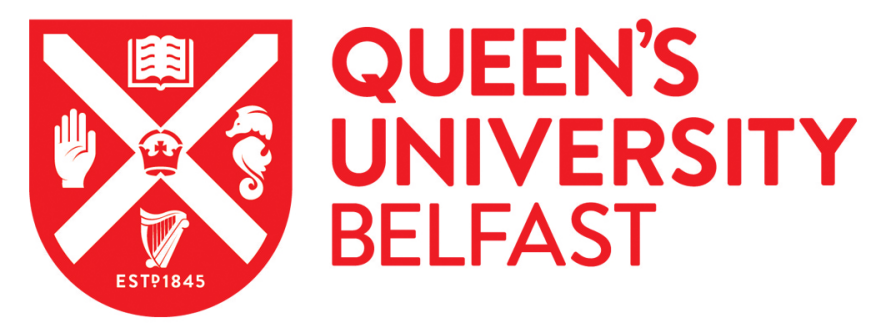

\title{
The Impact of debt and financial stress on health in Northern Irish households
}

French, D., \& McKillop, D. (2017). The Impact of debt and financial stress on health in Northern Irish households. Journal Of European Social Policy, 458-473. https://doi.org/10.1177/0958928717717657

Published in:

Journal Of European Social Policy

Document Version:

Peer reviewed version

Queen's University Belfast - Research Portal:

Link to publication record in Queen's University Belfast Research Portal

Publisher rights

Copyright 2017 SAGE. This work is made available online in accordance with the publisher's policies. Please refer to any applicable terms of use of the publisher.

\section{General rights}

Copyright for the publications made accessible via the Queen's University Belfast Research Portal is retained by the author(s) and / or other copyright owners and it is a condition of accessing these publications that users recognise and abide by the legal requirements associated with these rights.

Take down policy

The Research Portal is Queen's institutional repository that provides access to Queen's research output. Every effort has been made to ensure that content in the Research Portal does not infringe any person's rights, or applicable UK laws. If you discover content in the Research Portal that you believe breaches copyright or violates any law, please contact openaccess@qub.ac.uk. 


\title{
The Impact of debt and financial stress on health in Northern Irish households
}

\begin{abstract}
We analyse data collected from a survey of Northern Irish low-income households experiencing varying degrees of financial hardship and examine how debt affects health and health-related behaviours. Our results indicate that the subjective experience of feeling financially stressed has a robust relationship with most aspects of health including ability to self-care, problems performing usual activities, pain problems and psychological health. In contrast, neither the size of the debt, the type of debt nor the number of different lenders add any extra explanatory power. Additionally, our results indicate that the pathway from financial difficulties to worse health runs through worse diets and increased consumption of cigarettes and drugs. This research is timely as household debt burdens will soon surpass the high levels seen at the time of the financial crisis and the introduction of welfare reform in Northern Ireland will put additional strain on low-income households.
\end{abstract}

Keywords: Debt, financial stress, health. 


\section{Introduction}

Living standards in Northern Ireland (NI) have traditionally lagged behind other parts of the United Kingdom. The recent economic downturn has affected Northern Ireland harder than all other regions with a slower job recovery and a sharper decline in wage earnings among those working (Corlett et al. 2016). A regional house price bubble and subsequent crash after the financial crisis has left $41 \%$ of homeowners in Northern Ireland in negative equity (Milligan, 2014). A greater proportion of adults in Northern Ireland report problems with bills, credit commitments or arrears than in any other UK region (MAS, 2016). The labour market is weak with low employment rates and a particularly high long-term unemployment rate (DETI, 2016). Using the standard income-based measurement of poverty, $21 \%$ of people in Northern Ireland are currently living in poverty compared to $15 \%$ in the UK as a whole (DSD, 2015).

To support the economy, public spending has traditionally been about $25 \%$ higher than the UK average (Commons, 2014). Until recently, Northern Ireland has been spared the impact of the UK's government cuts to spending on public sector wages and social security. However, the Stormont House Agreement included measures to reduce the size of the Civil Service by 20,000 from 2015 prompting fears of rising unemployment (O'Hara, 2015). This agreement also allowed for the introduction of the 2012 Welfare Reform Act which had applied only to Great Britain into Northern Ireland in 2016/7. The Northern Irish Welfare Reform Mitigations Working Group recognising the hardship experienced by vulnerable children and adults elsewhere in the UK recommended a number of measures in January 2016 to mitigate the effects of the introduction of welfare reform. However, none of these

are intended to be long-term solutions and the entire package expires in 2020 (Tinson and McInnes, 2016).

NI anti-poverty strategies have lacked political commitment. In 2006, a direct rule government introduced 'Lifetime Opportunities' as the new anti-poverty strategy for Northern Ireland. It emphasised the need for cross-departmental coordination in tackling poverty 
and social inclusion including health inequalities. All NI political parties initially rejected the strategy but, when no alternative was developed, Lifetime Opportunities was adopted in 2008. A judicial review in 2015 found that, while the NI government had adopted the overarching framework of the strategy, a long-range plan did not exist and was incapable of being made to exist by the current combination of programmes and interventions.

The weak labour market, reductions in public spending and the lack of effective antipoverty strategies will push more Northern Irish households into financial difficulties. Financial difficulties have a wider social cost often unrecognised by policy-makers with consequences for individual mental and physical health. Studies indicate a clear relationship between financial worries and depression among mothers of infants (Reading and Reynolds, 2001) ; individuals on the verge of bankruptcy (Selenko and Batinic, 2011) ; and low-income families with children (Bridges and Disney, 2010). The recent financial crisis and government programmes of austerity throughout Europe have led to a rise in financial strain and higher levels of suicide, alcohol problems and mental illness especially in the absence of social protection (Karanikolos et al., 2013). There is a smaller literature on the effects of financial difficulties on physical health. Drentea and Lavrakas (2000) found that credit card debt and stress regarding debt are associated with self-reported health. The emotional responses to economic hardship lead to coping behaviours detrimental to health. Turunen and Hiilamo (2014) and Nelson et al. (2008) find that the financially-stressed more readily indulge in impulsive unhealthy behaviours.

In this paper, we make the following contributions to the literature on how debt and financial stress affect health. Using data collected from a study of Northern Irish low-income households experiencing varying degrees of financial difficulties, we confirm results found in a number of studies which emphasise the primacy of the psychological response to financial hardship over the actual level of financial hardship in the relationship with health. As we have a richer source of health information than in other studies of financial hardship, we also explore the dimensions of health affected by financial problems and the health-related 
behaviours by which they affect health. The range of financial data gathered allows us to also use both measures of the amount of debt and subjective measures of financial stress as well as a number of measures of the type of debt. Potential endogeneity of financial problems to health may confound results reported elsewhere and we therefore account for reverse causation using data on a number of individual financial characteristics which are plausibly unaffected by health. By selecting our study population at the margin of financial difficulties rather than by random sampling, we hope to more clearly identify the relationship between financial difficulties and health.

Our results indicate that neither the size of the debt, the type of debt nor the number of different lenders used affect health whereas the subjective experience of feeling financially stressed has a robust relationship with most aspects of health. In particular, financial stress negatively affects self-care problems, problems with performing usual activities, experiencing pain and feeling anxious or depressed. Our results indicate that the adverse effect of financial stress on health is mediated through worse health behaviours. Those experiencing financial hardship do not reduce consumption of alcohol and fast-food but have worse diets and increase consumption of cigarettes and drugs. We also find that those with higher levels of unsecured debt are more likely to visit a GP or healthcare professional. The implication of these findings is that policies targeted at those in financial difficulties should consider a greater role for debt counselling, information and advice as it is the negative emotional response to these problems that has the most deleterious effect on psychological distress and physical health. Recent government policy in Northern Ireland as in the rest of the UK has been to reduce funding to these services and there currently exists an 'advice gap' due to affordability particularly for low earners (FCA, 2016). 


\section{Literature review and conceptual model}

\subsection{Related literature}

The focus of the literature connecting debt and health primarily focuses on mental health. Reading and Reynolds (2001) found money worries to be the strongest predictor of depression scores among mothers of infants. Gathergood (2012) used local house price movements to establish causation from mortgage debt to psychological health. Selenko and Batinic (2011) find that perceived financial strain not the amount of debt affects mental health and Bridges and Disney (2010) show that this effect is robust to accounting for potential simultaneity. Fitch et al. (2011) provide an excellent review of this literature.

Although anecdotal evidence indicates a link between physical health and debt there has been little research in this area especially at household level. A number of studies have shown that, at country-level, the recent financial crisis has caused a decline in health status (e.g., Clayton et al., 2015). There have been fewer studies on the effect of household debt on health. In an important early study, Drentea and Lavrakas (2000) show the influence of credit card debt on physical impairment and self-reported health in a telephone survey of Ohio residents. Using a simple health measure, Lenton and Mosley (2008) estimate a model which accounts for reverse causation between debt and health using the UK Families and Children survey. More recently, Sweet et al. (2013) show that reporting high financial debt is related to worse self-reported general health and higher diastolic blood pressure in a study of US young adults. Keese and Schmitz (2014) find an association between household indebtedness and health satisfaction but not with obesity after controlling for unobserved heterogeneity using data from the German Socio-Economic Panel. More recently, Angel (2016) discusses how country-level factors moderate the effect of problematic debt on selfreported health. A common shortcoming in this literature is a lack of consideration of the potential endogeneity of debt. Also, the range of debt information and health information is limited because studies have not been designed with both these research areas in mind. 
Researchers are therefore often unable to consider variation of the impact of debt on health by type of debt or to consider the various channels by which debt can affect health directly.

There are a range of factors which cause household debt. Lifecycle planning allows households to plan consumption based on how much they expect to earn over their lifetimes and households will therefore enter debt during their early years knowing that they will have the resources to repay these loans later when incomes are higher (Ando and Modigliani, 1963). However, unexpected negative household financial shocks such as marital breakdown or withdrawal of welfare benefits can force households into over-indebtedness. Individual personality traits may also lead to financial hardship. A lack of confidence dealing with financial matters or a lack of financial literacy is associated with higher debt burdens, incurring greater fees, and defaults and delinquency (Disney and Gathergood, 2013). Materialistic individuals are more prone to compulsive spending (Garðarsdóttir and Dittmar, 2012) and poor money management skills lead to inattentiveness and poor financial decision-making (French and McKillop, 2014). Debt, in turn, affects health although many authors suggest only indirectly through subjective financial well-being (e.g. Bridges and Disney, 2010; Arber et al., 2014). In a systematic review of the available literature, Turunen and Hiilamo (2014) conclude that the causal link between indebtedness and health runs through an emotional response to financial difficulties of shame, failure, worry and concern. This response is moderated by an individual's attitudes to debt (Haultain et al., 2010), economic vulnerability (Worthington, 2006; del Rio and Young, 2008), the degree to which they can draw on the social capital of family and friends (Cohen and Wills, 1985) as well as constitutional factors e.g. resilience (Sood et al. 2011). Therefore people with the same level of financial difficulties according to objective measures will not report the same degree of financial stress.

Theory explaining why financial stress should also affect physical health has recently been forthcoming. The literature describes how financial worries consume mental resources preventing rational decision-making and depleting limited resources of self-control Mani et al., 2013; Vohs, 2013; Haushofer and Fehr, 2014). In an experiment, artificially elevating 
cortisol levels in participants caused an increase in temporal discounting Cornelisse et al. 2013). Nelson et al. (2008) find that the financially-stressed more readily indulge in impulsive behaviours such as overeating unhealthy foods, excessive consumption of drugs and alcohol, sedentary behaviour and physical fighting.

The epidemiological literature suggests that, in addition to changes in health behaviours, financial difficulties may influence health through biological pathways associated with stress more generally. Economic difficulties have been associated with a higher incidence of coronary events in the famous Whitehall study of health inequalities (Ferrie et al., 2005) and, in particular, financial strain has been observed to elevate triglyceride levels, a risk factor for heart disease, independently of changes in health behaviours or poor mental health Georgiades et al., 2009). Havlik et al. (1992) found that melanoma patients were more likely to have experienced a major financial crisis in the five years before clinical presentation than a control group perhaps reflecting greater susceptibility to this illness due to stress. Ochsmann et al. (2009) report a higher incidence of back pain among those who approached debt counselling agencies although the authors do not make it clear why this should be the case.

\subsection{Modelling strategy}

To estimate the degree of association between financial difficulties and health, we begin with a simple model assuming that financial difficulties exogenously influence health :

$$
h_{j}=\beta^{\prime} X_{j}+\gamma d_{j}+\epsilon_{j}
$$

where $h_{j}$ is a continuous measure of health for individual $j, X_{j}$ is a vector of exogenous control variables and $d_{j}$ is a measure of financial difficulties either objective (e.g. debt measures) or subjective (e.g. self-reported financial stress) and $\epsilon_{j}$ is a random error term. Our exogenous control variables are age, gender, whether respondent has partner, whether homeowner, household income, the number of children under five in household, educational 
qualifications and employment status.

However, $d_{j}$ may be endogenous in this relationship i.e. correlated with $\epsilon_{j}$. This may occur for two reasons. Firstly, in addition to financial difficulties causing health problems, poor health may also cause financial problems. Balmer et al. (2006) report that long-term illness or disability was the strongest predictor of debt problems in their analysis. Healthcare costs due to serious medical conditions may drive patients into bankruptcy (Himmelstein et al., 2009). Houle and Keene (2014) find that illness increases the risk of mortgage default and foreclosure. A second form of endogeneity which arises for subjective reports of financial difficulties is discussed by Bridges and Disney (2010). They focused on mental health and argue that those suffering from poor mental health will be more inclined to see a given set of financial circumstances in an adverse light. The same argument could also apply to reports of physical health where, for example, a mentally draining illness such as back pain might lead the sufferer to negatively view their financial situation.

Allowing for the potential endogeneity of financial difficulties results in the following model :

$$
\begin{aligned}
& h_{j}=\beta^{\prime} X_{j}+\gamma d_{j}+\epsilon_{j} \\
& d_{j}^{*}=\delta^{\prime} W_{j}+u_{j}
\end{aligned}
$$

and the binary variable $d_{j}$ is generated by the unobservable latent variable $d_{j}^{*}$ according to

$$
d_{j}= \begin{cases}1, & \text { if } d_{j}^{*}>0 \\ 0, & \text { otherwise }\end{cases}
$$

where the error terms $\epsilon_{j}$ and $u_{j}$ are bivariate normal with mean zero and covariance 
matrix

$$
\left(\begin{array}{cc}
\sigma^{2} & \rho \sigma \\
\rho \sigma & 1
\end{array}\right)
$$

The cross-equation correlation parameter $\sigma$ accounts for any unobserved association between self-reports of health and financial difficulties.

\section{Data}

\subsection{Survey and Data collection}

Five Northern Irish credit unions located in Greater Belfast and Newry, Co.Down participated in our study. Northern Irish credit unions have historically been very successful and play a very significant role in the financial sector here particularly in low-income communities. In 2011, there were 181 credit unions in Northern Ireland and $26 \%$ of the Northern Irish population were members of a credit union (McKillop and Wilson, 2011).

Management in these five credit unions identified 1,091 of their members with either loans in arrears for greater than 9 weeks or loans that had been rescheduled. They wrote to these members explaining the study and highlighting that they had been chosen for interview on the basis of their arrears position. The rationale for this approach was to make respondents aware that the interviewers would know they were in debt and hence they would be less inclined to underreport the level and extent of their debts as in other studies (Zinman, 2009: Karlan and Zinman, 2008). Where there was more than one indebted member in the household, the interviewee was the member available for interview if they were joint account holders at the credit union. Otherwise the interviewee was chosen at random. As a result, 36 individuals were dropped from the target population. The survey was carried out from January to April 2014 by a local market research company resulting in 499 completed surveys giving a response rate of $47 \%$. The survey was carried out face-to-face and lasted approximately one hour. The questionnaire consisted of modules on household demographics, 
employment, income and benefits, debt, expenditure, savings and assets, financial literacy and financial characteristics as well as a number of health-related questions.

Our first debt measure was formed by summing responses to 'How much do you currently owe...' on loans from bank/building society, credit union, internet money lender, high street loan shop, home collection loan agency, unauthorised money lender, friend/relative, employer and other (e.g. social fund, student loan). Bank overdrafts, credit card commitments as well as arrears on household bills (rent, electricity, fuel, rates and other utilities) were added to this total. The respondent was also instructed to consider partner's debt if not already included. The log of the ratio of this measure to weekly household income is our unsecured debt variable. To construct our measure of secured debt, we first calculate mortgage debt from questions on total household expenditure and the percentage of this budget spent on mortgages. This figure is then annualised and multiplied by the number of years left on the mortgage. Any outstanding car loans are also added to this total and the log of the ratio of this total to weekly household income is our secured debt variable. Additionally, a variable reflecting the number of different lenders used and a variable indicating use of high-interest financing were constructed.

We also collected information on subjective financial well-being. Respondents are asked 'Thinking back over the past 12 months, how often would you say you have had trouble with debts that you found hard to repay...'. There are four possible answers to this question : 'Almost all the time', 'Quite often' , 'Only sometimes' and 'Never'. Following Bridges and Disney (2010), we classify those who report trouble 'Almost all the time' or 'Quite often' as having persistent debt troubles. The next question asks 'How often would you say you have money over at the end of the week, or end of the month if you budget by month? Would you say it was...'. There were six possible answers and we classify households with money over 'Hardly ever' or 'Never' as having budget difficulties. Our last question on financial stress is 'Taking everything together, which of these phrases best describes how you are managing financially these days?'. Households with 'some financial difficulties' or 'in deep 
financial trouble' were deemed to be not managing financially. We regard individuals as being in financial stress if they have persistent debt troubles or budget difficulties or are not managing financially.

Our main measures of health are responses to questions on five dimensions of health from the EQ-5D questionnaire (The EuroQol Group, 1990). Respondents state if they have (1) no problems, (2) some problems, or (3) severe problems with their mobility, self-care, ability to perform usual activities, pain/discomfort, and anxiety/depression. Each respondent then has one of 243 possible health states e.g. 11111, 32132. These were then transformed to a quality-of-life scale using time-trade-off data from a nationally representative UK health valuation study (Dolan, 1997) where death and full health are assigned scores of 0 and 1 respectively.

A number of additional variables provide us with suitable instruments in our instrumental variables regressions. Financial confidence is measured from responses to the question 'When you are shown information about a financial product such as a loan, credit card or store card, on a scale of 1 to 5 , how confident are you that you understand the total amount you would need to repay?'. Financial literacy is measured from four simple mathematical problems on simple interest, percentage, division and compound interest. Garðarsdóttir and Dittmar (2012) provide the survey questions to measure money management skills and materialism. Financial confidence has been associated with good financial decision-making (Robb and Woodyard, 2011); higher levels of financial literacy lead to less sub-prime mortgage delinquency (Gerardi et al., 2010), lower credit card fees (Lusardi and Tufano, 2009) and less high-cost borrowing (Disney and Gathergood, 2013) ; poor money managers tend to have arrears in household bills and higher credit card debt (Lea et al., 1995) and those with materialistic values have more financial worries and a greater tendency towards compulsive buying and spending (Garðarsdóttir and Dittmar, 2012). 


\subsection{Descriptive statistics}

Selected descriptive statistics for our study population are reported in Table 1 along with statistics for the Northern Irish population where available. Our study has slightly more females than expected and less than one-third are aged over 50. The average unsecured debt is $£ 4,021$ but further analysis shows considerable variation with 78 having no debt:11 and 95 having debts of over $£ 5,000$. The average secured debt is $£ 17,438$ (378 households report no secured debt). Incomes are substantially lower than the general population and participants in our study are experiencing considerable financial stress. On each of the three indicators - debt trouble, no money over and not managing - about one-half report difficulties. These figures are substantially higher than elsewhere in the population.

The proportion of those with problems on the dimensions of the EQ-5D are generally higher in the study population than in the NI population especially the proportion of respondents with some or severe problems with anxiety/depression. The poorer mental health is also borne out by the 12-item General Health Questionnaire (GHQ-12) where a score of 4 or more indicates the presence of psychiatric morbidity and $28 \%$ of our study population compared to $19 \%$ of the population have a high score. The other dimensions of the EQ$5 \mathrm{D}$ index are very similar to national levels and reports of some or severe pain/discomfort problems are actually lower but we will see later than these aggregate statistics mask large variation by debt levels.

In order to additionally understand the channels by which debt affects health, our survey contained a module on health-related behaviours including smoking, drinking, physical activity, diet and consumption of illegal drugs. The diet of our study group appears to be poor with $14 \%$ not having enough to eat compared to $2 \%$ nationally and a much smaller proportion $(19 \%)$ than nationally $(33 \%)$ eating the recommended five portions of fruit and vegetables per day. There is a much higher proportion of current smokers than the general population

\footnotetext{
${ }^{1}$ The survey was carried out two to six months after participants were identified as being in arrears to the credit union. These individuals have therefore eliminated their debts in this period.
} 
but the percentage drinking alcohol is much lower. Only $7 \%$ have taken non-prescription substances (e.g. cannabis, cocaine) in the last 4 weeks which is very similar to the Northern Irish figure. Our study population, as a whole, appears to have a higher percentage meeting the Northern Irish Chief Medical Officer's recommended levels of physical activity. As the UK National Health Service is publicly-funded, financial difficulties do not restrict access to healthcare services and, in fact, our study population are more likely to have visited a GP or healthcare professional in the last two weeks than the general population.

\section{[Insert Table 1 near here]}

\section{Results}

\subsection{Debt, financial stress and health}

Our first set of estimates are given in Table 2 for the simple model (1) explaining health where all debt variables are regarded as being exogenous. The dependent variable is the EQ5D index score and our control variables are age, gender, whether respondent has partner, whether homeowner, household income and the number of children under five, educational qualifications and employment status. We progressively add measures of debt across the four columns to assess the robustness of results. In the first regression, we see that health monotonically worsens with age as a lower EQ-5D index score indicates worse health. Being over 50 reduces the EQ-5D index score by around 0.17 compared to the 18-24 reference age category. Educational qualifications make little difference to health except for workrelated qualifications which increase the EQ-5D index score by 0.14 when compared to the reference category who have no educational qualifications. Being employed also makes a large statistically significant difference to the EQ-5D index. Of most interest to this study, we also see that debt lowers our index of health but find that the effect is confined to secured debt. However, when we move to our second regression where we add subjective 
questions on financial well-being, this variable is no longer significant whereas 'not managing' significantly lowers health. The effect is large (-0.087) considering the range of the index and is of the order of the effect of moving from the 18-24 reference age category to being aged 35-49 (-0.093). In the third regression, we also consider the number of different lenders used in the last three years as having multiple loans means multiple repayment schedules, more paperwork, greater chance of missing repayments and potentially higher interest rates (Meltzer et al., 2012). In the fourth regression, high-interest financing is also considered as debts of this form rapidly spiral and these lenders use more aggressive methods to compel repayment (Lusardi and Scheresberg, 2013). The coefficient on 'not managing' is unchanged throughout whereas these additional variables do not add any extra explanatory power to the regression. The other two measures of subjective financial stress, 'debt trouble' and 'no money over', are statistically insignificant in all of the different model specifications.

\section{[Insert Table 2 near here]}

A number of tests of the robustness of these results to the potential endogeneity of our subjective measures of financial well-being are conducted in Table 3. The three separate measures are combined into the 'financial stress' variable described above. Estimates can be found in two stages by first estimating an equation explaining financial stress and using fitted values from this regression to estimate the parameters of the health equation. The best statistical approach to carrying out this two-stage approach depends on the assumptions we make about the model. If the explanatory variables or instruments are only weakly correlated with financial stress then limited information maximum likelihood (LIML) used in (1) provides a robust estimation procedure (Hahn et al., 2004). If we know for certain that the relationship between financial stress and the instruments is given by a probit model, a more efficient estimator is available (Wooldridge, 2002) and is used in (2). In (3), we estimate the financial stress and health equations in one step using maximum likelihood (ML) estimation (Maddala, 1986). While this approach is more efficient it may potentially 
be less robust to misspecification (Wooldridge, 2007).

Valid instruments must be correlated with financial stress but uncorrelated with the error term in the health equation and correctly excluded from this equation. We use our discussion in subsection 2.1 to guide us in which instruments should theoretically satisfy these criteria. The instruments used are the exogenous variables that affect debt but are not affected in turn by health (financial confidence, financial literacy, money management skills, materialism). In (1), the coefficient estimate indicates a large effect of financial stress on health but this estimate has a large standard error. As before, unsecured and secured debt provide no additional explanatory power. In (2), the estimate of the effect of financial stress on health is smaller than before $(-0.314)$ but still within the confidence intervals of estimates from model (1). The treatment-effects model in (3) gives the most conservative estimate but the effect is still very large (-0.235) and is greater than the positive effect of being employed or not (0.208 - not shown in table). This estimate is most precise but as noted earlier this model may potentially be less robust to misspecification.

The models are correctly specified with acceptance of the null hypothesis that the instruments are valid i.e. uncorrelated with the error term and correctly excluded from the estimated equation (Hansen-J test) and rejection of the null hypothesis that the instruments are irrelevant i.e. uncorrelated with financial stress (Underidentification test). Tests are also included for weak identification i.e. instruments are weakly correlated with financial stress. Weak identification can lead to bias and misleading inference. Both tests, the Cragg-Donald test and the Kleibergen-Paap test, are generally above the $10 \%$ maximal size critical value indicating that weak identification appears not to be a problem. However, as a precaution, we have used the LIML estimation approach which is more robust to weak identification. Importantly, the difference-in-Hansen endogeneity test rejects the hypothesis that financial stress can be treated as exogenous thus necessitating instrumental variable approaches. In the treatment effects model in column (3), violation of the assumption that the error terms in the first stage financial stress equation and the second stage health equation are correlated 
can lead to estimation bias. Rejection of equation independence suggests that applying the treatment effects model is appropriate.

A clear picture emerges then from this set of regressions. Financial stress is endogenous and we therefore must use instrumental variables approaches. The issue of endogeneity of debt-related variables was neglected in many of the studies in this area thus compromising estimates. All regressions point towards a large negative effect of financial stress on the EQ-5D index of health with a range of estimates varying between -0.235 and -0.487 .

We conducted two further checks on the robustness of these results which are not reported here (though available on request). We first repeated the regressions reported in Table 3 with 'not managing' as the only endogenous measure of subjective financial well-being. Secondly,

we instrumented secured and unsecured debt as well as financial stress. Results are very similar to those reported here. The debt measures are statistically insignificant and 'financial stress' is statistically significant and of the same size as in Table 3.

\section{[Insert Table 3 near here]}

\subsection{Debt and dimensions of health}

As mental health constitutes one of the five dimensions of the EQ-5D index, the relationship between financial stress and health could be driven by the already well-established connection between mental health and debt. In the next step, we estimate the relationship between debt and each of the EQ-5D dimensions separately using a recursive bivariate probit model. The dependent variable in each case is coded 1 if the respondent has some or severe problems with the particular dimension of health and 0 otherwise. Controls are as before and the full instrument set described above is used for financial stress. Results are presented in Table 4. We see that financial stress does not just impact on mental health but on almost all dimensions of health captured by this index. The effect is greatest for mental health where the coefficient presented equates to a $58 \%$ increase in the probability of having 
problems with anxiety or depression due to financial stress. But financial stress also increases the probability of reporting self-care problems, the probability of having problems with performing usual activities and the probability of having problems with pain. Our subjective measure of financial well-being has no significant effect on problems with mobility. Secured and unsecured debt have no statistically significant effect except for the anxiety-depression dimension where unsecured debt has a small effect. The coefficient presented equates to a $0.04 \%$ increase in the probability of having problems with anxiety or depression due to a $1 \%$ increase in unsecured debt.

\section{[Insert Table 4 near here]}

\subsection{The chain of causation from debt to health}

Having established the positive association of financial stress with dimensions of health we explore the causal mechanisms by which this association could occur in our final set of estimates (Table 5). We concentrate here on how health-related behaviours change with levels of financial stress. As discussed in subsection 2.1, stress may also cause cardiovascular disease and some cancers through biological pathways which are independent of changes in behaviours. However, collecting information on appropriate biomarkers to identify these effects was outside the scope of this study.

The consumption of unhealthy goods (e.g.alcohol, cigarettes, fast-food) requires disposable income and therefore it could be argued that the financially-stressed should consume less of these goods. On the other hand, theory suggests that financial worries cause stress which, in turn, induces short-sighted decision-making (Haushofer and Fehr, 2014) and therefore, in

our study, we would expect a lower tendency to engage in goal-directed health behaviours (e.g. diet, physical activity) in those who are most in debt.

Our estimates tend to agree with these arguments. The dependent variables are a mix of binary, ordinal and continuous variables and we will focus on the sign and magnitude 
of the coefficients. Controls and instruments are as before. Financial stress lowers the number of portions of fruit and vegetables consumed daily and reduces the probability that an individual will achieve the recommended levels of physical activity but the latter result is not statistically significant. On the consumption side, those who are financially stressed do not consume alcoholic drinks more frequently nor do they visit fast-food outlets more frequently. However, they smoke many more cigarettes per week and they have a higher probability of taking non-prescription substances. These conflicting results can perhaps be explained by how the influences of the force of present-biases increasing demand and the force of a lack of disposable income reducing demand vary for each unhealthy consumption good. For the more addictive goods (cigarettes and drugs), the present-bias wins out while for the less addictive goods (alcohol and fast-food) the opposing forces balance. This type of reasoning could be accommodated within the rational theory of addiction proposed by Becker and Murphy (1988) which models the consumption of an addictive good in terms of its degree of addictiveness, individual time preference as well as income and other economic parameters.

Unlike Nelson et al. (2008), we find that debt measures have little association with any of these behaviours. The only estimate that is significant is for the effect of unsecured debt on physical activity where debt appears to act in an unexpected way improving activity levels.

As the UK National Health Service is publicly-funded, financial difficulties should not restrict access to healthcare services. The financially stressed are no less likely to have visited a GP or healthcare professional in the past two weeks. In fact, the statistically significant positive coefficient on unsecured debt would indicate an increase in GP attendance due to high debt levels.

\section{[Insert Table 5 near here]}




\section{Conclusion}

High levels of financial stress due to recession and government programmes of austerity are being experienced in many European countries. Cross-country comparisons of the effects on health draw attention to the current limited body of evidence on causal mechanisms and appropriate policy responses (Quaglio et al., 2013; Haw et al., 2014).

In our study of low-income households in Northern Ireland, we find that levels of financial stress matter for physical health and health-related behaviours confirming findings in some other recent studies. In addition, our finding that the subjective experience of feeling financially stressed has a robust relationship with most aspects of health whereas neither the size of the debt, the type of debt nor the number of different lenders add any additional explanatory power contributes to this research area. Perceptions of debt may be providing additional information not reflected in actual debt levels such as the unavailability of coping mechanisms to deal with the burden of debt. We also add to the existing literature by examining the causal pathways from financial difficulties to health. Our results indicate that the pathway runs through worse diets and increased consumption of cigarettes and drugs.

Households in Northern Ireland have been faced with greater financial problems than elsewhere in the UK and proposed cuts in public spending will increase financial stress. The $£ 585 \mathrm{~m}$ Welfare Reform mitigations package currently under consideration are temporary measures due to expire in 2020. The majority of funds will go on supplementary payments to ease the transition to lower benefit levels while the independent advice sector will be given $£ 8 \mathrm{~m}$ to provide advice and support to clients through the transition. Although a small sum, this will go some way towards addressing the stress caused by complex changes to the welfare system. There is no acknowledgement in the package of the likely increased GP workload as a result of their patients' financial hardship and the impact on other health and social services (Iacobucci et al., 2014; Iacobucci, 2014). An even smaller sum (£800,000) will be allocated to a financial capability program and a pilot scheme to encourage those in financial difficulties to access socially responsible lending such as credit unions. Credit 
unions could play a bigger role in financial capability in Northern Ireland as one of their core operating principles is financial education of their members in order to promote thrift and the wise use of credit. Although most Northern Irish credit unions are engaged in some form of financial education in the community, the majority are low-commitment activities with marginal impact (Byrne et al., 2010).

Northern Ireland's anti-poverty strategy which could help address the consequences of public spending cuts has thus far lacked political commitment. The NI Executive has many programmes and interventions dealing with poverty, social exclusion and patterns of deprivation but action is disjointed and lacks a coordinated long-term plan. It is also argued that the current strategy overly focuses on child poverty and emphasizes economic policy solutions over social policy (Tinson and McInnes, 2016).

Northern Irish health policy has been innovative in recognising the social and economic determinants of health in its strategic frameworks for health and wellbeing : 'Investing for Health' (2002/2012) and 'Making Life Better' (2013/2023). These include actions on ensuring appropriate family-based financial support to children, providing young people with an awareness of budget management and encouraging long-term financial independence. Our study reinforces the importance of these initiatives for health as they will encourage sound financial decision-making and help individuals avoid debt. However, we would emphasize a greater role of debt counselling, information and advice for NI consumers in financial difficulties as it is the negative emotional response to these problems that has the most deleterious effect on health. The NI Financial Capability Strategy, currently out to consultation, promises actions on departmental provision of free face-to-face, telephone and on-line debt advice as well as working through third sector organisations to support the most financially vulnerable in dealing with and managing debt. With adequate resources, these services would make a real difference to improving the physical and mental health of financially stressed households.

Funding to financial counselling services in Northern Ireland as in other parts of the 
UK has been significantly reduced in recent years. The Financial Inclusion Fund which supported the work of 500 debt advisers throughout the UK was closed in March 2011, there have been reductions in civil legal aid and citizens advice (Hynes, 2013) and the national free debt and financial advice service is soon to be abolished (FT, 2016). A recent national review highlighted the need for these services as levels of financial literacy are low and there exists an 'advice gap' due to affordability particularly for low earners (FCA, 2016). The implications of these cuts for financial stress, anxiety and welfare merit further research.

Our study has a greater breadth of information than in other research linking financial difficulties and health as we used a survey purposely designed to capture many aspects of debt, physical health and health behaviours. This has allowed us to go beyond simple summary measures of health and consider the impact of both objective and subjective measures of debt on a range of dimensions of health. In addition, we consider potential mediating variables in order to understand how such effects might occur. Also, our empirical analysis considers the issue of endogeneity in greater detail than elsewhere.

There are a number of limitations to this study. Ideally, we would have interviewed all members of the household to elicit information about all debts held but this was not feasible. The subjective financial wellbeing measures did not distinguish between attitudes to debt and attitudes to arrears. Robust information on financial assets would also have enhanced the analysis. 


\section{References}

Ando, A. and F. Modigliani (1963). The "life cycle" hypothesis of saving: Aggregate implications and tests. The American Economic Review 53(1), 55-84.

Angel, S. (2016). The Effect of Over-Indebtedness on Health: Comparative Analyses for Europe. Kyklos 69(2), 208-227.

Arber, S., K. Fenn, and R. Meadows (2014). Subjective financial well-being, income and health inequalities in mid and later life in Britain. Social Science $\&$ Medicine 100, 12-20.

Balmer, N., P. Pleasence, A. Buck, and H. C. Walker (2006). Worried sick: The experience of debt problems and their relationship with health, illness and disability. Social Policy and Society 5(1), $39-51$.

Baum, C. F., M. E. Schaffer, and S. Stillman (2007). Enhanced routines for instrumental variables / GMM estimation and testing. Stata Journal 7(4), 465-506.

Becker, G. S. and K. M. Murphy (1988). A theory of rational addiction. Journal of Political Economy 96(4), pp. 675-700.

Bridges, S. and R. Disney (2010). Debt and depression. Journal of Health Economics 29(3), 388403.

Byrne, N., C. Power, O. McCarthy, and M. Ward (2010). The potential for impact of credit unions on members financial capability: An exploratory study,. Combat Poverty Agency, Working Paper Series: $10 / 08$.

Clayton, M., J. Liñares-Zegarra, and J. O. Wilson (2015). Does debt affect health? Cross country evidence on the debt-health nexus. Social Science $\&$ Medicine 130, 51-58.

Cohen, S. and T. A. Wills (1985). Stress, social support, and the buffering hypothesis. Psychological Bulletin 98(2), 310.

Commons (2014). Public sector employment and expenditure by region, SN/EP/5625., Volume 14. House of Commons Library. Available at http://researchbriefings.parliament.uk.

Corlett, A., D. Finch, and M. Whittaker (2016). Living Standards 2016 The experiences of low to middle income households in downturn and recovery. Resolution Foundation. Available at http://www.resolutionfoundation.org.

Cornelisse, S., V. Van Ast, J. Haushofer, M. Seinstra, and M. Joels (2013). Time-dependent effect of hydrocortisone administration on intertemporal choice. SSRN id:2294189.

Cragg, J. G. and S. G. Donald (1993). Testing identifiability and specification in instrumental variable models. Econometric Theory 9(02), 222-240.

del Rio, A. and G. Young (2008). The impact of unsecured debt on financial pressure among British households. Applied Financial Economics 18(15), 1209-1220.

DETI (2016). Northern Ireland Labour Market Report March 2016. Department of Enterprise, Trade and Industry. Available at https://www.detini.gov.uk. 
Disney, R. and J. Gathergood (2013). Financial literacy and consumer credit portfolios. Journal of Banking \& Finance 37(7), 2246-2254.

Dolan, P. (1997). Modeling valuations for EuroQol health states. Medical Care 35(11), 1095-1108.

Drentea, P. and P. J. Lavrakas (2000). Over the limit: the association among health, race and debt. Social Science \&s Medicine 50(4), 517-529.

DSD (2015). Households Below Average Income Northern Ireland 2013-14. Department for Social Development. Available at www.dsdni.gov.uk/.

FCA (2016). Financial Advice Market Review Final Report. Financial Conduct Authority.

Ferrie, J., P. Martikainen, M. Shipley, and M. Marmot (2005). Self-reported economic difficulties and coronary events in men: evidence from the Whitehall II study. International Journal of Epidemiology 34(3), 640-648.

Fitch, C., S. Hamilton, P. Bassett, and R. Davey (2011). The relationship between personal debt and mental health: a systematic review. Mental Health Review Journal 16(4), 153-166.

French, D. and D. G. McKillop (2014). Financial literacy and over-indebtedness in low-income households. SSRN id:2505084.

FT (2016). Unfit Money Advice Service to be scrapped in Budget. Financial Times https://next.ft.com/content/604c11bc-eaef-11e5-888e-2eadd5fbc4a4.

Garðarsdóttir, R. B. and H. Dittmar (2012). The relationship of materialism to debt and financial well-being: The case of Iceland's perceived prosperity. Journal of Economic Psychology 33(3), $471-481$.

Gathergood, J. (2012). Debt and depression: Causal links and social norm effects. The Economic Journal 122(563), 1094-1114.

Georgiades, A., I. Janszky, M. Blom, K. D. László, and S. Ahnve (2009). Financial strain predicts recurrent events among women with coronary artery disease. International Journal of Cardiology $135(2), 175-183$.

Gerardi, K., L. Goette, and S. Meier (2010). Financial literacy and subprime mortgage delinquency: Evidence from a survey matched to administrative data. Federal Reserve Bank of Atlanta Working Paper Series (2010-10).

Guo, S. and M. W. Fraser (2014). Propensity Score Analysis: Statistical Methods and Applications: Statistical Methods and Applications, Volume 11. Sage Publications.

Hahn, J., J. Hausman, and G. Kuersteiner (2004). Estimation with weak instruments: Accuracy of higher-order bias and mse approximations. The Econometrics Journal 7(1), 272-306.

Hansen, L. P. (1982). Large sample properties of generalized method of moments estimators. Econometrica: Journal of the Econometric Society, 1029-1054.

Haultain, S., S. Kemp, and O. S. Chernyshenko (2010). The structure of attitudes to student debt. Journal of Economic Psychology 31(3), 322-330. 
Haushofer, J. and E. Fehr (2014). On the psychology of poverty. Science 344(6186), 862-867.

Havlik, R. J., A. P. Vukasin, and S. Ariyan (1992). The impact of stress on the clinical presentation of melanoma. Plastic and Reconstructive Surgery 90(1), 57-61.

Haw, C., K. Hawton, D. Gunnell, and S. Platt (2014). Economic recession and suicidal behaviour: possible mechanisms and ameliorating factors. International journal of social psychiatry, 0020764014536545 .

Hayashi, F. (2000). Econometrics. Princeton University Press. Section 1, 60-69.

Himmelstein, D. U., D. Thorne, E. Warren, and S. Woolhandler (2009). Medical bankruptcy in the United States, 2007: Results of a national study. The American Journal of Medicine 122(8), $741-746$.

Houle, J. N. and D. E. Keene (2014). Getting sick and falling behind: health and the risk of mortgage default and home foreclosure. Journal of Epidemiology and Community Health, forthcoming.

Hynes, S. (2013). Austerity justice. Journal of Poverty and Social Justice 21(1), 97-100.

Iacobucci, G. (2014). GPs increasingly have to tackle patients' debt and housing problems. BMJ 349:94301.

Iacobucci, G. et al. (2014). GPs workload climbs as government austerity agenda bites. BMJ 349, g4300.

Karanikolos, M., P. Mladovsky, J. Cylus, S. Thomson, S. Basu, D. Stuckler, J. P. Mackenbach, and M. McKee (2013). Financial crisis, austerity, and health in europe. The Lancet 381(9874), $1323-1331$.

Karlan, D. and J. Zinman (2008). Lying about borrowing. Journal of the European Economic Association 6(2-3), 510-521.

Keese, M. and H. Schmitz (2014). Broke, ill, and obese: Is there an effect of household debt on health? Review of Income and Wealth 60(3), 525-541.

Kleibergen, F. and R. Paap (2006). Generalized reduced rank tests using the singular value decomposition. Journal of Econometrics 133(1), 97-126.

Lea, S. E., P. Webley, and C. M. Walker (1995). Psychological factors in consumer debt: Money management, economic socialization, and credit use. Journal of Economic Psychology 16(4), $681-701$.

Lenton, P. and P. Mosley (2008). Debt and health. Sheffield Economic Research Paper Series SERP No. 2008004 .

Lusardi, A. and C. d. B. Scheresberg (2013). Financial literacy and high-cost borrowing in the United States. National Bureau of Economic Research NBER No. 18969.

Lusardi, A. and P. Tufano (2009). Debt literacy, financial experiences, and overindebtedness. Technical report, National Bureau of Economic Research. 
Maddala, G. S. (1986). Limited-dependent and qualitative variables in econometrics. Number 3. Econometric Society Monographs No. 3, Cambridge University Press.

Mani, A., S. Mullainathan, E. Shafir, and J. Zhao (2013). Poverty impedes cognitive function. Science 341(6149), 976-980.

MAS (2016). A Picture of Over-Indebtedness. Money Advice Service. Available at https://www.moneyadviceservice.org.uk/en/corporate/debt-publications.

McKillop, D. and J. O. Wilson (2011). Credit unions: A theoretical and empirical overview. Financial Markets, Institutions $\&$ Instruments 20(3), 79-123.

Meltzer, H., P. Bebbington, T. Brugha, M. Farrell, and R. Jenkins (2012). The relationship between personal debt and specific common mental disorders. The European Journal of Public Health, $1-6$.

Milligan (2014). Negative Equity Afflicts Half A Million Households. Available from http://www.bbc.co.uk/news/business-26389009.

Nelson, M. C., K. Lust, M. Story, and E. Ehlinger (2008). Credit card debt, stress and key health risk behaviors among college students. American Journal of Health Promotion 22(6), 400-407.

Ochsmann, E. B., H. Rueger, S. Letzel, H. Drexler, and E. Muenster (2009). Over-indebtedness and its association with the prevalence of back pain. BMC Public Health 9(1), 451.

O'Hara, M. (2015). Austerity Bites: A journey to the sharp end of cuts in the UK. Policy Press.

Quaglio, G., T. Karapiperis, L. Van Woensel, E. Arnold, and D. McDaid (2013). Austerity and health in europe. Health Policy 113(1), 13-19.

Reading, R. and S. Reynolds (2001). Debt, social disadvantage and maternal depression. Social Science 85 Medicine 53(4), 441-453.

Robb, C. A. and A. Woodyard (2011). Financial knowledge and best practice behavior. Journal of Financial Counseling and Planning 22(1).

Selenko, E. and B. Batinic (2011). Beyond debt. A moderator analysis of the relationship between perceived financial strain and mental health. Social Science $\&$ Medicine 73(12), 1725-1732.

Sood, A., K. Prasad, D. Schroeder, and P. Varkey (2011). Stress management and resilience training among department of medicine faculty: a pilot randomized clinical trial. Journal of General Internal Medicine 26(8), 858-861.

Stock, J. H. and M. Yogo (2005). Testing for weak instruments in linear IV regression. Identification and inference for econometric models: Essays in honor of Thomas Rothenberg SSRN id:1734933.

Sweet, E., A. Nandi, E. K. Adam, and T. W. McDade (2013). The high price of debt: Household financial debt and its impact on mental and physical health. Social Science 8 Medicine 91, 94-100.

The EuroQol Group (1990). EuroQol-a new facility for the measurement of health-related quality of life. Health Policy 16(3), 199-208. 
Tinson, A. and T. McInnes (2016). Monitoring Poverty and Social Exclusion in Northern Ireland. New Policy Institute and the Poverty Alliance for the Joseph Rowntree Foundation. Available at http://npi.org.uk/publications.

Turunen, E. and H. Hiilamo (2014). Health effects of indebtedness: a systematic review. $B M C$ public health 14(1), 489.

Vohs, K. D. (2013). The poor's poor mental power. Science 341(6149), 969-970.

Wooldridge, J. M. (2002). Economic Analysis of Cross Section and Panel Data. Cambridge: MIT Press.

Wooldridge, J. M. (2007). Lecture Notes 6 - Whats New in Econometrics? National Bureau of Economic Research Summer Institute 2007 http://www.nber.org/minicourse3.html.

Worthington, A. C. (2006). Debt as a source of financial stress in Australian households. International Journal of Consumer Studies 30(1), 2-15.

Zinman, J. (2009). Where is the missing credit card debt? Clues and implications. Review of Income and Wealth 55(2), 249-265. 
Table 1: Descriptive statistics

\begin{tabular}{|c|c|c|c|c|}
\hline \multirow[b]{2}{*}{ Variable } & \multicolumn{3}{|c|}{ Sample } & \multirow{2}{*}{$\begin{array}{c}\text { NI } \\
\text { Mean }\end{array}$} \\
\hline & Mean & Std. dev. & Range & \\
\hline \multicolumn{5}{|l|}{ Demographics } \\
\hline Female & $58 \%$ & & & \\
\hline Aged 25-34 & $28 \%$ & & & \\
\hline Aged 35-49 & $34 \%$ & & & \\
\hline Over 50 & $31 \%$ & & & \\
\hline Has GCSEs & $30 \%$ & & & \\
\hline Work-related qualifications & $12 \%$ & & & \\
\hline Has A Levels & $16 \%$ & & & \\
\hline Has degree & $10 \%$ & & & \\
\hline Homeowner & $45 \%$ & & & \\
\hline Employed & $56 \%$ & & & \\
\hline Has partner & $38 \%$ & & & \\
\hline Partner employed & $66 \%$ & & & \\
\hline $\begin{array}{l}\text { No. of children under-5 in household } \\
\text { Income and debts }\end{array}$ & 2.2 & 1.2 & 7 & \\
\hline Unsecured debt & $£ 4,021$ & $£ 10,090$ & $£ 150,300$ & \\
\hline Secured debt & $£ 17,438$ & $£ 53,846$ & $£ 523,301$ & \\
\hline Household weekly income & $£ 290$ & $£ 196$ & $£ 995$ & $£ 454$ \\
\hline Debt trouble & $42 \%$ & & & $7 \%$ \\
\hline No money over & $58 \%$ & & & $22 \%$ \\
\hline Not managing & $52 \%$ & & & $5 \%$ \\
\hline No. of lenders & 1.1 & 0.8 & 5 & \\
\hline High-interest loan last year & $8 \%$ & & & \\
\hline \multicolumn{5}{|l|}{ Health } \\
\hline EQ-5D index score & 0.81 & 0.30 & 1.3 & \\
\hline Mobility problems & $17 \%$ & & & $15 \%$ \\
\hline Self-care problems & $8 \%$ & & & $8 \%$ \\
\hline Usual activities problems & $18 \%$ & & & $17 \%$ \\
\hline Pain/discomfort problems & $26 \%$ & & & $31 \%$ \\
\hline Anxiety/depression problems & $33 \%$ & & & $26 \%$ \\
\hline High GHQ12 score & $28 \%$ & & & $19 \%$ \\
\hline Not enough to eat & $14 \%$ & & & $2 \%$ \\
\hline Fruit \& veg $(5+$ a day $)$ & $19 \%$ & & & $33 \%$ \\
\hline Eat fast food & $57 \%$ & & & \\
\hline Currently smoke & $41 \%$ & & & $24 \%$ \\
\hline Drink alcohol & $58 \%$ & & & $81 \%$ \\
\hline Illegal drugs (aged <60) & $7 \%$ & & & $5 \%$ \\
\hline Physically active & $72 \%$ & & & $60 \%$ \\
\hline Seen GP last 2 weeks & $35 \%$ & & & $23 \%$ \\
\hline $\mathrm{N}$ & 499 & & & \\
\hline
\end{tabular}


Notes: Unsecured and secured debt are given as the figures reported by participants before the transformation described in the text. Physically active implies meeting the NI Chief Medical Officer's guidelines. Over a week, activity should add up to at least 150 minutes of moderate intensity activity or alternatively 75 minutes of vigorous intensity activity or a combination of moderate and vigorous intensity activity. Source for NI data is Health Survey Northern Ireland 2013/14. These figures are standardised to the age and sex distribution of our study population. Exceptions are Illegal drugs 2010/11 Northern Ireland Drug Prevalence Survey Debt trouble, No money over, Not managing 2009/10 Continuous Household Survey Household weekly income 2013/14 Continuous Household Survey. These figures are unstandardised. 
Table 2: Estimates of the impact of financial problems on health

\begin{tabular}{|c|c|c|c|c|}
\hline & $\begin{array}{c}(1) \\
\text { coef./s.e. }\end{array}$ & $\begin{array}{c}(2) \\
\text { coef./s.e. }\end{array}$ & $\begin{array}{c}(3) \\
\text { coef./s.e. }\end{array}$ & $\begin{array}{c}\text { (4) } \\
\text { coef./s.e. }\end{array}$ \\
\hline \multirow[t]{2}{*}{ Female } & 0.000 & -0.012 & -0.011 & -0.010 \\
\hline & $(0.024)$ & $(0.024)$ & $(0.025)$ & $(0.025)$ \\
\hline \multirow[t]{2}{*}{ Aged 25-34 } & -0.014 & -0.008 & -0.006 & -0.001 \\
\hline & $(0.037)$ & $(0.035)$ & $(0.036)$ & $(0.036)$ \\
\hline \multirow[t]{2}{*}{ Aged 35-49 } & $-0.096^{*}$ & $-0.093^{*}$ & $-0.092^{*}$ & -0.082 \\
\hline & $(0.045)$ & $(0.044)$ & $(0.044)$ & $(0.044)$ \\
\hline \multirow[t]{2}{*}{ Over 50} & $-0.174^{* * *}$ & $-0.178^{* * *}$ & $-0.173^{* * *}$ & $-0.163^{* * *}$ \\
\hline & $(0.049)$ & $(0.048)$ & $(0.049)$ & $(0.048)$ \\
\hline \multirow[t]{2}{*}{ Has GCSEs } & 0.059 & 0.062 & 0.063 & 0.061 \\
\hline & $(0.037)$ & $(0.038)$ & $(0.037)$ & $(0.038)$ \\
\hline \multirow[t]{2}{*}{ Work-related qualifications } & $0.138^{* * *}$ & $0.137^{* * *}$ & $0.136^{* * *}$ & $0.134^{* * *}$ \\
\hline & $(0.038)$ & $(0.037)$ & $(0.037)$ & $(0.037)$ \\
\hline \multirow[t]{2}{*}{ Has A Levels } & 0.050 & 0.047 & 0.050 & 0.044 \\
\hline & $(0.042)$ & $(0.042)$ & $(0.043)$ & $(0.042)$ \\
\hline \multirow[t]{2}{*}{ Has degree } & 0.064 & 0.059 & 0.053 & 0.063 \\
\hline & $(0.051)$ & $(0.051)$ & $(0.053)$ & $(0.053)$ \\
\hline \multirow[t]{2}{*}{ Homeowner } & 0.025 & 0.021 & 0.022 & 0.014 \\
\hline & $(0.031)$ & $(0.031)$ & $(0.032)$ & $(0.032)$ \\
\hline \multirow[t]{2}{*}{ Employed } & $0.229^{* * *}$ & $0.220^{* * *}$ & $0.222^{* * *}$ & $0.221^{* * *}$ \\
\hline & $(0.031)$ & $(0.031)$ & $(0.031)$ & $(0.031)$ \\
\hline \multirow[t]{2}{*}{ Has partner } & 0.029 & 0.027 & 0.028 & 0.017 \\
\hline & $(0.031)$ & $(0.031)$ & $(0.031)$ & $(0.031)$ \\
\hline \multirow[t]{2}{*}{ No. of children under- 5} & -0.007 & -0.005 & -0.005 & -0.001 \\
\hline & $(0.012)$ & $(0.012)$ & $(0.012)$ & $(0.011)$ \\
\hline \multirow[t]{2}{*}{ Household income } & 0.007 & 0.009 & 0.006 & 0.008 \\
\hline & $(0.018)$ & $(0.019)$ & $(0.020)$ & $(0.020)$ \\
\hline \multirow[t]{2}{*}{ Unsecured debt } & -0.017 & -0.011 & -0.015 & -0.016 \\
\hline & $(0.011)$ & $(0.011)$ & $(0.012)$ & $(0.013)$ \\
\hline \multirow[t]{2}{*}{ Secured debt } & $-0.015^{*}$ & -0.014 & -0.014 & -0.013 \\
\hline & $(0.007)$ & $(0.007)$ & $(0.007)$ & $(0.007)$ \\
\hline \multirow[t]{2}{*}{ Debt trouble } & & -0.015 & -0.017 & -0.012 \\
\hline & & $(0.032)$ & $(0.032)$ & $(0.032)$ \\
\hline \multirow[t]{2}{*}{ No money over } & & 0.050 & 0.050 & 0.046 \\
\hline & & $(0.030)$ & $(0.031)$ & $(0.030)$ \\
\hline \multirow[t]{2}{*}{ Not managing } & & $-0.087^{* *}$ & $-0.087^{* *}$ & $-0.092^{* *}$ \\
\hline & & $(0.029)$ & $(0.029)$ & $(0.030)$ \\
\hline \multirow[t]{2}{*}{ No. of lenders } & & & 0.013 & 0.011 \\
\hline & & & $(0.020)$ & $(0.022)$ \\
\hline \multirow[t]{2}{*}{ High-interest loan last year } & & & & -0.021 \\
\hline & & & & $(0.059)$ \\
\hline \multirow[t]{2}{*}{ Constant } & $0.727^{* * *}$ & $0.732^{* * *}$ & $0.738^{* * *}$ & $0.733^{* * *}$ \\
\hline & $(0.104)$ & $(0.110)$ & $(0.112)$ & $(0.113)$ \\
\hline$R^{2}$ & 0.278 & 0.294 & 0.295 & 0.296 \\
\hline $\mathrm{N}$ & 476 & 476 & 476 & 470 \\
\hline
\end{tabular}

Notes : In a small number of cases, respondents refused to answer some of the borrowing questions resulting in different sample sizes for our regressions. ${ }^{*} p<0.05,{ }^{* *} p<0.01,{ }^{* * *} p<0.001$. 
Table 3 : Estimates of the impact of financial problems on health using instrumental variables

\begin{tabular}{lccc}
\hline \hline & $(1)$ & $(2)$ & $(3)$ \\
& LIML & Woofdridge & ML \\
& coef./s.e. & coef./s.e. \\
Cnsecured debt & -0.001 & -0.009 & -0.016 \\
& $(0.015)$ & $(0.013)$ & $(0.012)$ \\
Secured debt & 0.002 & -0.004 & -0.013 \\
& $(0.010)$ & $(0.008)$ & $(0.007)$ \\
Financial stress & $-0.487^{* *}$ & $-0.314^{* *}$ & $-0.235^{* * *}$ \\
& $(0.161)$ & $(0.100)$ & $(0.053)$ \\
\hline Underidentification test & $50.4^{* * *}$ & $42.2^{* * *}$ & \\
Weak identification tests & & & \\
$\quad$ Cragg-Donald & 3.04 & 46.79 & \\
$\quad$ Kleibergen-Paap & 4.02 & 48.02 & \\
$\quad$ 10\% maximal size & 3.31 & 16.38 & \\
Hansen J test & 12.6 & & \\
Endogeneity test & $11.6^{* * *}$ & $8.5^{* *}$ & \\
Test of indep. eqns. & & & $14.8^{* * *}$ \\
N & 470 & 470 & 470 \\
\hline \hline
\end{tabular}

Notes : All models include controls used in final regression of Table 2. Model 1 - LIML with instruments \{Financial confidence, Financial literacy, Money management skills, Materialism\}. Model 2 - Wooldridge procedure using fitted probabilities of financial stress. Model 3 - ML estimation of treatment effects model. Standard errors are robust to heteroscedasticity. The underidentification test is the rk LM test (Kleibergen and Paap, 2006). The critical values provided for the weak identification tests (Cragg and Donald, 1993: Kleibergen and Paap, 2006) require the assumption of i.i.d. errors (Stock and Yogo, 2005). Critical values have not been developed for the case of heteroscedasticity and following Baum et al. (2007), the Stock-Yogo critical values are applied to the Kleibergen-Paap test statistic with caution. The Hansen $\mathrm{J}$ test is a test of overidentifying restrictions (Hansen, 1982). The endogeneity test is the difference of two Sargan-Hansen statistics (Hayashi, 2000). The test of independent equations is a Wald test (Guo and Fraser, 2014). ${ }^{*} p<0.05,{ }^{* *} p<0.01,{ }^{* * *} p<0.001$

Table 4 : Estimates of the impact of financial problems on health dimensions

\begin{tabular}{lccccc}
\hline \hline & $\begin{array}{c}\text { Mobility } \\
\text { problems }\end{array}$ & $\begin{array}{c}\text { Self- } \\
\text { care } \\
\text { problems }\end{array}$ & $\begin{array}{c}\text { Usual } \\
\text { activities } \\
\text { problems }\end{array}$ & $\begin{array}{c}\text { Pain } \\
\text { problems }\end{array}$ & $\begin{array}{c}\text { Anxiety/ } \\
\text { depression } \\
\text { problems }\end{array}$ \\
\hline Unsecured debt & 0.012 & 0.013 & 0.001 & 0.116 & $0.111^{*}$ \\
& $(0.075)$ & $(0.092)$ & $(0.068)$ & $(0.060)$ & $(0.046)$ \\
Secured debt & 0.010 & 0.129 & 0.026 & 0.034 & 0.007 \\
Financial stress & $(0.057)$ & $(0.080)$ & $(0.056)$ & $(0.038)$ & $(0.031)$ \\
& 0.512 & $1.122^{*}$ & $1.099^{*}$ & $0.983^{*}$ & $1.611^{* * *}$ \\
\hline Log-likelihood & $(0.530)$ & $(0.484)$ & $(0.428)$ & $(0.409)$ & $(0.212)$ \\
$\mathrm{N}$ & -392.5 & -342.7 & -397.2 & -457.8 & -479.9 \\
\hline \hline
\end{tabular}

Notes : Recursive bivariate probit models estimated by limited-information maximum likelihood. All models include the full set of instruments and full set of controls. Standard errors are robust to heteroscedasticity. ${ }^{*} p<0.05,{ }^{* *} p<0.01,{ }^{* * *} p<0.001$ 
Table 5 : Estimates of the impact of financial problems on health behaviours

\begin{tabular}{lccccccc}
\hline \hline & GP & Cigs. & Drink & Active & $\begin{array}{c}\text { Fast } \\
\text { food } \\
\text { coef./s.e. }\end{array}$ & $\begin{array}{c}\text { Fruit } \\
\text { \& veg } \\
\text { coef./s.e. }\end{array}$ & Drugs \\
& coef./s.e. & coef./s.e. & coef./s.e. & coef./s.e. & coef. \\
\hline Unsecured debt & $0.105^{*}$ & -2.764 & -0.045 & $0.114^{*}$ & -0.010 & 0.050 & -0.058 \\
& $(0.053)$ & $(2.691)$ & $(0.041)$ & $(0.055)$ & $(0.052)$ & $(0.031)$ & $(0.058)$ \\
Secured debt & 0.032 & -1.356 & -0.022 & -0.068 & -0.030 & -0.029 & -0.008 \\
& $(0.035)$ & $(1.941)$ & $(0.030)$ & $(0.039)$ & $(0.036)$ & $(0.021)$ & $(0.048)$ \\
Financial stress & 0.562 & $48.540^{*}$ & 0.795 & -0.837 & 0.654 & $-1.450^{* * *}$ & $1.195^{*}$ \\
& $(0.388)$ & $(23.989)$ & $(0.536)$ & $(0.562)$ & $(0.457)$ & $(0.126)$ & $(0.528)$ \\
\hline $2^{\text {nd } \text { stage model }}$ & Probit & Continuous & Ordered & Probit & Probit & Ordered & Probit \\
& & & Probit & & & Probit & \\
$\mathrm{N}$ & 499 & 471 & 499 & 499 & 499 & 499 & 499 \\
\hline \hline
\end{tabular}

Notes : GP - Have you consulted your GP or other health professional in the past two weeks? Cigs.

- Cigarettes smoked per week. Drink - How often have you had an alcoholic drink of any kind during the last 12 months? Response on scale 1-8. Active - Achieving NI Chief Medical Officer's recommended levels of physical activity. Fast food - Can you tell me how often do you visit fast-food outlets? Fruit $\mathcal{E}$ veg - How many portions of fruit and vegetables do you eat each day? Drugs - During the last 4 weeks have you taken any non-prescription substances? (i.e. illegal drugs) 